\title{
Energy Evolution and AE Failure Precursory Characteristics of Rocks with Different Rockburst Proneness
}

\author{
Feng Pei $\mathbb{D}^{1,2}$ Hongguang Ji $\mathbb{D}^{1,2}$ Jiwei Zhao, ${ }^{1,2}$ and Jingming Geng ${ }^{1,2}$ \\ ${ }^{1}$ School of Civil and Resource Engineering, University of Science and Technology Beijing, Beijing 100083, China \\ ${ }^{2}$ Beijing Key Laboratory of Urban Underground Space Engineering, University of Science and Technology Beijing, \\ Beijing 100083, China \\ Correspondence should be addressed to Hongguang Ji; 1078938768@qq.com
}

Received 7 April 2020; Revised 16 May 2020; Accepted 25 May 2020; Published 15 June 2020

Academic Editor: Hailing Kong

Copyright (c) 2020 Feng Pei et al. This is an open access article distributed under the Creative Commons Attribution License, which permits unrestricted use, distribution, and reproduction in any medium, provided the original work is properly cited.

\begin{abstract}
Mastering the precursory information of rock failure is the basis of scientifically predicting rockburst, and AE technology is an effective means to solve this problem. The conventional uniaxial loading and cyclic loading/unloading tests of metagabbro and granite were carried out with GAW-2000 uniaxial electrohydraulic rigid testing machine to evaluate rockburst proneness. The energy evolution and $\mathrm{AE}$ characteristics of rocks with different rockburst proneness during loading are revealed. The results show that the rockburst proneness of granite is obviously stronger than that of metagabbro based on the comprehensive evaluation method of multiple rockburst proneness index. The reasons for different rockburst proneness are analyzed from the perspective of mineral composition and microstructure. Rockburst proneness is positively correlated with energy storage capacity. The elastic energy ratio of granite is obviously larger than that of metagabbro before peak stress. The intensity of AE signals generated in the failure process of strong rockburst rock (granite) is significantly higher than that of moderate rockburst rock (metagabbro). However, the peak frequency bands and amplitude all increase obviously before failure. The $b$-value and memory characteristics of rock with different rockburst proneness have obvious similar change rules.
\end{abstract}

\section{Introduction}

With the depletion of shallow resources, a great number of countries have gradually entered the deep mining stage. Rockburst disaster occurred frequently, which posed a great threat to the safety of equipment, life, and property. Rock is a heterogeneous material due to its petrographic, mineralogical, and internal microstructure features that affect the engineering properties of this rock. Rock stores elastic energy in the form of elastic strain, while it consumes energy in the form of crack propagation and damage. When the rock is loaded to its ultimate bearing capacity, aggregated strain energy in rock mass is released rapidly, thereby causing massive attack. In the meantime, a large number of $\mathrm{AE}$ signals are released in the form of elastic waves. AE signals contain a lot of information about crack propagation and coalescence. It could infer internal structure alteration and failure mechanism under different stress levels, and then the rockburst could be effectively predicted based on AE signals.

Considerable research on rock energy evolution has been undertaken, and scholars have achieved many important research results. Xie et al. [1,2], for example, reveal the essential characteristics of rock instability and failure from the energy point of view, which lays a foundation for energy evolution analysis of rock mechanics. Nonlinear characteristics and energy distribution proportion of red sandstone were investigated by Zhang and Gao $[3,4]$ through uniaxial and triaxial cyclic loading/unloading testing. The relationship between energy conversion and rock fragmentation was clarified [5]. Li et al. [2] carried out uniaxial loading/ unloading tests of rocks at different loading speeds and obtained the variation of releasable strain energy and dissipation energy. In addition, a large number of scholars have studied the relationship between rock damage and energy evolution [6-8]. However, little attention has been paid to 
study the differences in the energy evolution of rocks with different rockburst proneness.

The deformation and failure of rocks have been investigated by analyzing AE signals, and studies have shown that information from the AE signals can be used to monitor the development of internal cracks in rocks and serve as an early warning for the instability and failure of rocks. Scholars have done a lot of research studies on AE signals from characteristic parameters and spectrum characteristics. On the one hand, AE signals are used to study the evolution process of rock fracture development by characteristic parameters such as ring counting rate, event rate, and energy rate. On the other hand, the combination of characteristic parameters such as RA (rising time/amplitude) $[9,10]$ and $\mathrm{AF}$ (counting/duration) is used to study the variation of parameters in the loading process. In the research of spectrum characteristics, Ji $[11,12]$ pointed out that the sudden increase of high-frequency and high-amplitude AE signals indicates that granite will be destabilized with the increase of stress level. The main frequency distribution band of $\mathrm{AE}$ signals in the process of rockburst is revealed [13-16].

Rockburst proneness is the inherent property of rock. The research of rockburst proneness is the basis of predicting and preventing rockburst and has important guiding significance for dynamic disasters. Engineering practice shows that rock is commonly loaded cyclically during construction. However, there are few comparison studies on energy evolution and $\mathrm{AE}$ characteristics of rocks with different rockburst proneness during cyclic loading/unloading. In this study, uniaxial cyclic loading/unloading testing is conducted on rocks with different rockburst proneness, and energy evolution and $\mathrm{AE}$ characteristics of rocks with different rockburst proneness are obtained. Felicity ratio was used to characterize the damage memory characteristics of two kinds of rocks during loading/ unloading. At the same time, the development law of AE $b$ value is revealed, which provides a theoretical basis for the prediction of rock failure. The relationship between damage evolution, energy accumulation and release, and AE precursor information before the failure of rocks with different rockburst proneness is clarified.

\section{Comprehensive Evaluation of Rockburst Proneness Based on Multiple Criteria}

Rockburst must have two necessary conditions [17]: (1) rock has the ability to store high strain energy, which releases enormous energy in the failure process, and (2) excavation disturbance brings about local energy concentration, which provides energy for rockburst. In this work, a large number of laboratory experiments have been carried out for the first necessary condition. In view of the limitation of a single index to evaluate rockburst proneness, the rockburst proneness is evaluated by brittleness coefficient $B$, maximum elastic energy density Es, and rockburst tendency index Wet.

2.1. Brittleness Coefficient B. The strength brittleness coefficient could be defined as the ratio of uniaxial compressive strength $\left(\sigma_{\mathrm{c}}\right)$ to uniaxial tensile strength $\left(\sigma_{\mathrm{t}}\right)$ :

$$
B=\frac{\sigma_{\mathrm{c}}}{\sigma_{\mathrm{t}}},
$$

where $\sigma_{\mathrm{c}}$ is the uniaxial compressive strength and $\sigma_{\mathrm{t}}$ is the tensile strength. The average tensile strength of granite and metagabbro is $7.82-9.14 \mathrm{MPa}$ and $6.75-8.64 \mathrm{MPa}$, respectively.

2.2. Maximum Elastic Energy Density Es. The maximum elastic strain energy density before the peak strength indicates the energy storage capacity of rock, which provides sufficient energy support for the dynamic impact of rock after failure. Several typical uniaxial compression curves and failure patterns are shown in Figure 1:

$$
\mathrm{Es}=\frac{R_{\mathrm{c}}^{2}}{2 E},
$$

where $\sigma_{\mathrm{c}}$ is the uniaxial compressive strength (UCS), MPa; $E$ is Young's modulus, MPa.

2.3. Rockburst Proneness Index Wet. The rockburst proneness index is a quantitative parameter, which corresponds to the ratio between the storage energy and the consumption energy in the loading stage, i.e., the loading measures $80-90 \%$ of the peak strength and the unloading measures $5 \%$ of the peak stress. The rockburst proneness index is the ratio between the elastic strain energy recovered during the unloading process and the dissipation energy in the loading process. The larger the rockburst proneness index is, the more likely an impact occurs in case of failure. Typical loading and unloading curves and failure patterns are shown in Figure 2.

Based on the comprehensive evaluation result in Table 1, it could be concluded that although there are small differences in rockburst proneness discriminant results between the different criteria, metagabbro shows a weak or moderate rockburst proneness, while granite shows a strong rockburst proneness. The impact intensity of granite is obviously stronger than that of metagabbro.

\section{Microstructure Characteristics}

Many research studies have clarified that the mechanical behavior of rock and energy storage capability are essentially determined by mineral composition, micromorphology, and combination mode [18-25]. The mineral composition and micromorphology characteristics of two kinds of rocks are obtained by combining powder X-ray diffraction (XRD) and binocular transmission polarization microscopy. The results are shown in Figures 3 and 4.

The metagabbro is grey-green, with scaly-columnar and fibrous metamorphic textures and banded and massive structures. It is mainly composed of amphibole (30\%), feldspar (45\%), quartz (15\%), biotite (5\%), kaolin (3\%), and chlorite (2\%). The composition is not uniform, which mainly shows the difference of altered mineral content caused by different alteration intensity. The minerals have the characteristics of directional arrangement under the microscope. 


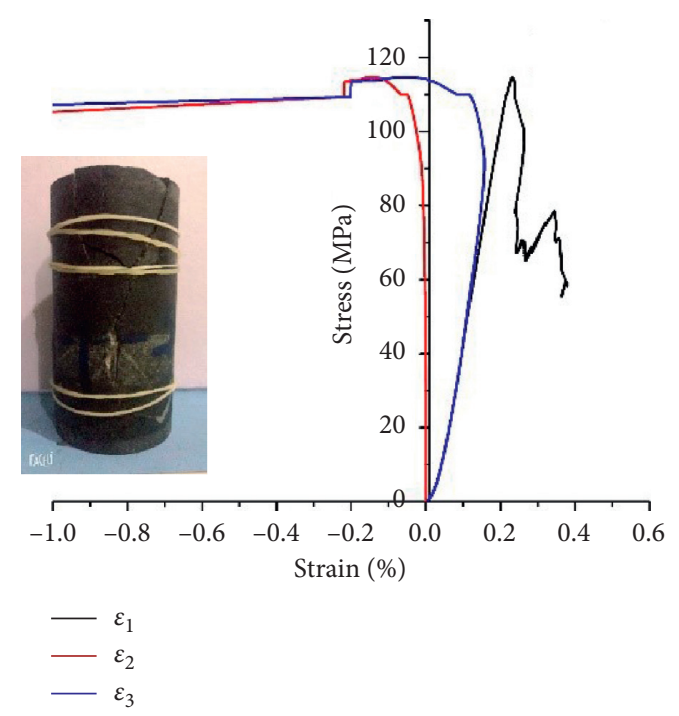

(a)

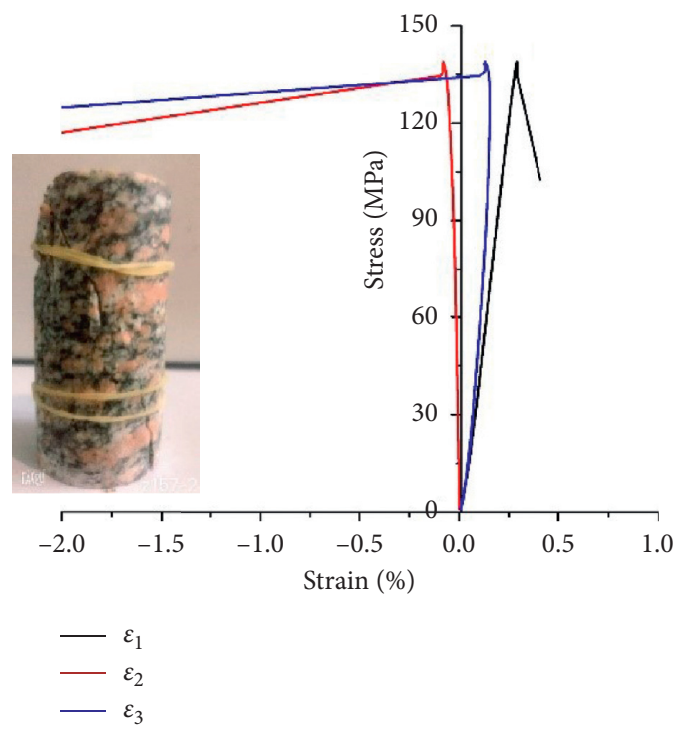

(c)

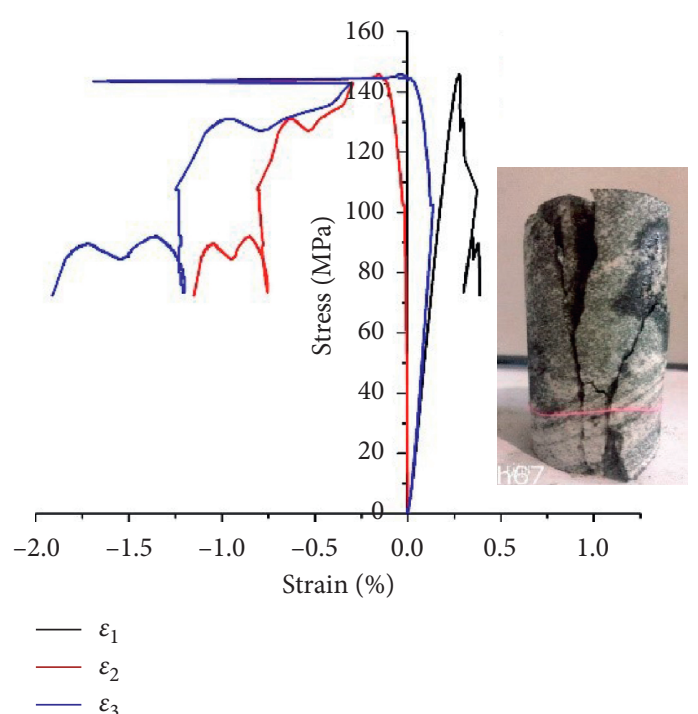

(b)

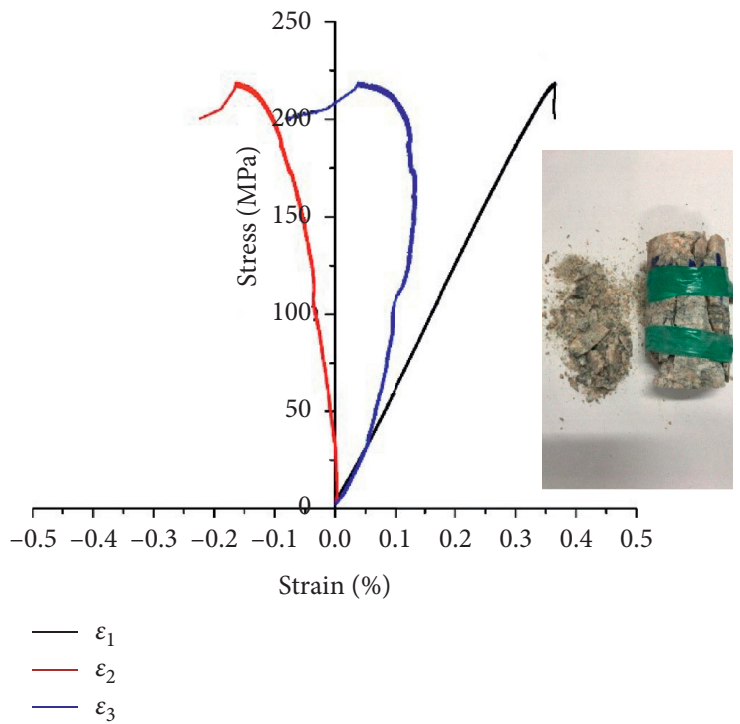

(d)

Figure 1: (a) Metagabbro-1, (b) metagabbro-2, (c) granite-1, and (d) granite-2.

The particle size distribution is shown in Figure 3(d), and the equivalent radius is mainly distributed in the range of $0.04-0.2 \mathrm{~mm}$.

Comprehensive analysis shows that the granite has a porphyry-like structure with obvious schistosomiasis. The porphyry is feldspar (60\%) with a grain size of about $0.5 \mathrm{~mm}$. The matrix is mainly quartz (30\%). The dark minerals are mainly biotite (5\%) with directional arrangement. Other minerals include chlorite (about $3 \%$ ) and pyrite (about $2 \%$ ). The equivalent radius is mainly distributed in the range of $0.2-0.75 \mathrm{~mm}$.

Quartz has compact structure, high stiffness, good mechanical properties, and small dispersion. The texture of feldspar is relatively soft than that of quartz, and its mechanical properties are relatively discrete. Mica is a soft material with obvious pore structure and great dispersion of mechanical properties. Quartz and feldspar with stable mechanical properties in granite are obviously higher than that in metagabbro, which is the key element affecting rock impact proneness. Meanwhile, the crystallization degree is also the key factor affecting rockburst proneness.

\section{Energy Evolution Characteristics}

4.1. Specimen Preparation. Samples used in the experiments are granite and metagabbro, which were collected from the main shaft geological exploration hole of Shanling gold mine in Laizhou, Shandong Province. According to the method recommended by ISRM, samples were cylindrical cores drilled with diameters of $50 \mathrm{~mm}$ and lengths of $100 \mathrm{~mm}$. To reduce the dispersion of experimental results caused by the natural differences in rock specimens, specimens with fewer cracks and no obvious defects were selected for experiments. 


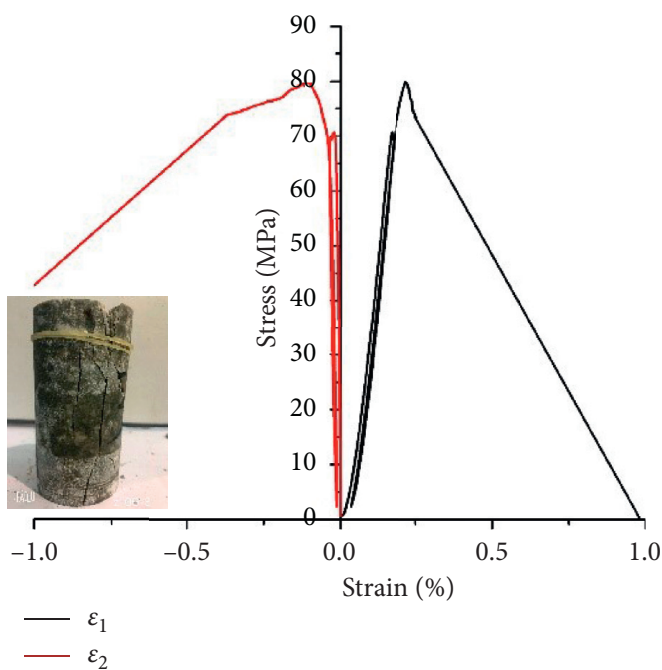

(a)

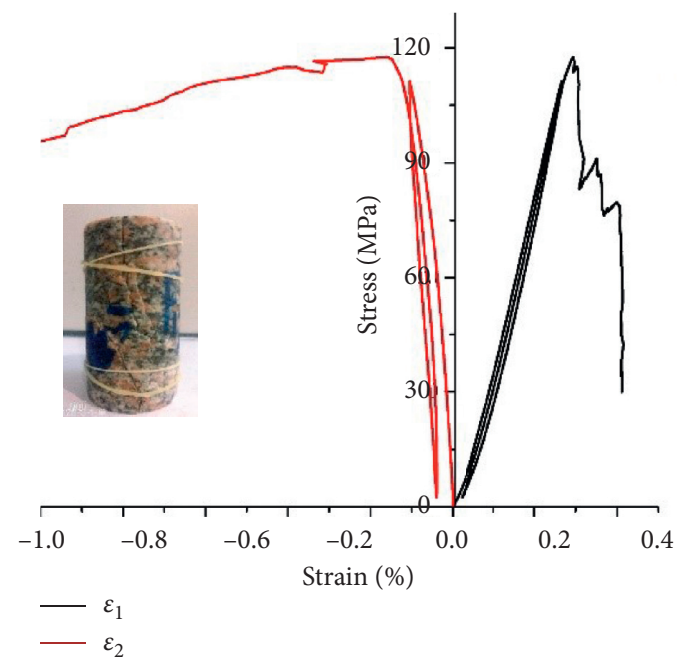

(b)

Figure 2: The loading and unloading curves of (a) metagabbro and (b) granite.

TABLE 1: Rockburst prediction results based on multiple criteria.

\begin{tabular}{|c|c|c|c|c|c|c|c|}
\hline \multirow[t]{2}{*}{ Lithology } & \multirow[t]{2}{*}{ Depth (m) } & \multicolumn{2}{|c|}{$\begin{array}{l}\text { Maximum elastic strain } \\
\text { energy density }\end{array}$} & \multicolumn{2}{|c|}{ Brittleness index } & \multicolumn{2}{|c|}{$\begin{array}{l}\text { Rockburst proneness } \\
\text { index }\end{array}$} \\
\hline & & Es & Level & $B$ & Level & Wet & Level \\
\hline Metagabbro & 761 & 172.9 & III & 14.9 & III & 3.76 & III \\
\hline Metagabbro & 965 & 145.5 & III & 14.7 & III & 3.47 & II \\
\hline Metagabbro & 1090 & 146.8 & III & 13.4 & III & 3.82 & III \\
\hline Granite & 1415 & 247.0 & IV & 16.77 & III & 7.98 & IV \\
\hline Granite & 1524 & 321.0 & IV & 19.5 & IV & 6.32 & IV \\
\hline Granite & 1526 & 410.59 & IV & 21 & IV & 5.16 & IV \\
\hline
\end{tabular}

II: weak rockburst proneness; III: moderate rockburst proneness; IV: strong rockburst proneness.

4.2. Test Procedures. The testing schemes were as follows: granite and metagabbro specimens were loaded/unloaded at a rate of $0.01 \mathrm{~mm} / \mathrm{min}$ in steps of $30 \mathrm{kN}$. In order to prevent the specimen from sliding off the compression head, the loading was only unloaded to $2 \mathrm{kN}$ in each cyclic step. The loading/unloading cycles were repeated until the specimen failed. AE signals were recorded with a processing system using a gain of $40 \mathrm{~dB}$ and a trigger amplitude threshold of $40 \mathrm{~dB}$. AE monitoring systems and the loading system were turned on simultaneously to acquire the AE data and the mechanical parameters.

4.3. Energy Evolution. The relationship between energy density and strain in uniaxial cyclic loading/unloading is depicted in Figure 5.

It can be seen that energy density has an obvious nonlinear relationship with strain and the energy evolution of rock with different rockburst proneness demonstrates obvious similarity characteristics.

The input energy density and elastic strain energy density almost coincide, and storing elastic strain energy is dominated in the elastic deformation stage. Due to internal crack initiation and propagation with stress level enhancement, input energy density deviates from elastic strain energy gradually. Small-scale crack propagation is dominated, and dissipation energy density increases slowly. Small-scale cracks are generating continuously and largescale cracks are starting to develop, more energy was consuming when entering the unsteady crack propagation stage, and the closer to the peak strength is, the greater the increase of dissipated energy density is until destroyed. The storage elastic energy density of granite and metagabbro at the peak strength is $0.248 \mathrm{MJ} \cdot \mathrm{m}^{-3}$ and $0.152 \mathrm{MJ} \cdot \mathrm{m}^{-3}$, respectively. The stronger the impact proneness is, the larger the energy storage capacity is.

In order to characterize the relationship between energy distribution ratios in the loading process, the energy storage ratio is defined as the ratio of elastic strain energy density to input energy density, and the ratio of dissipated energy density to input energy density is energy dissipation ratio. Energy storage ratio and energy dissipation ratio are calculated in Figure 6. As shown from Figure 6 that the dissipation ratio could be divided into four stages: decreasing, stabilization, slow increase, and sharp increase. In Figure 6, the dissipation ratio of metagabbro in the compaction stage is 0.267 ; however the dissipation ratio of granite in the compaction stage is 0.133 . The dissipation ratio of 


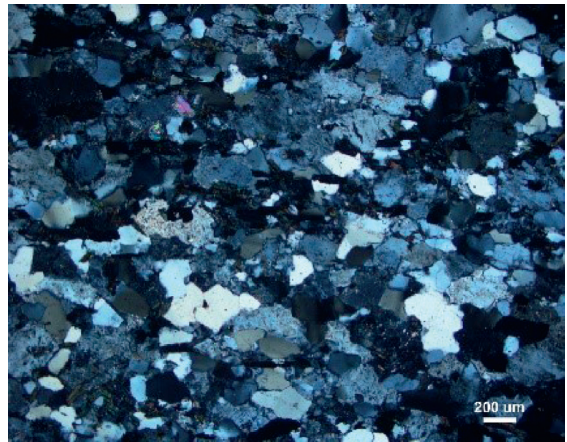

(a)

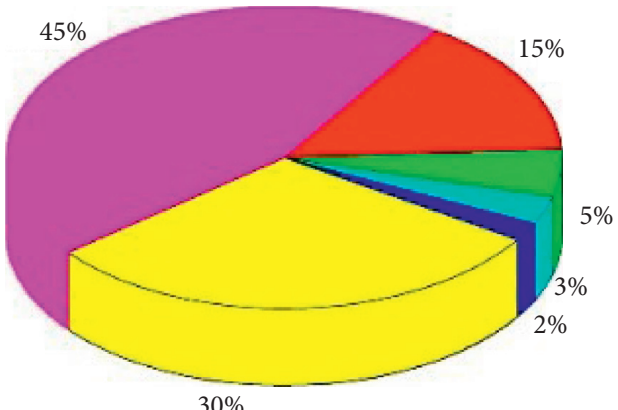

Hornblende

Feldspar

Quartz

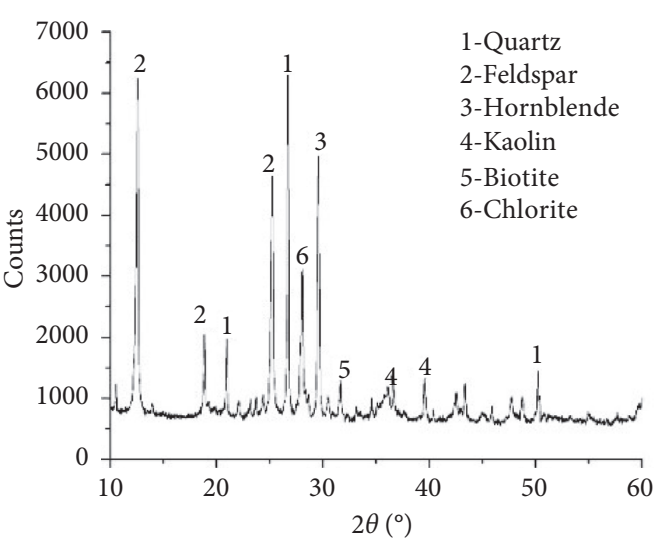

(b)

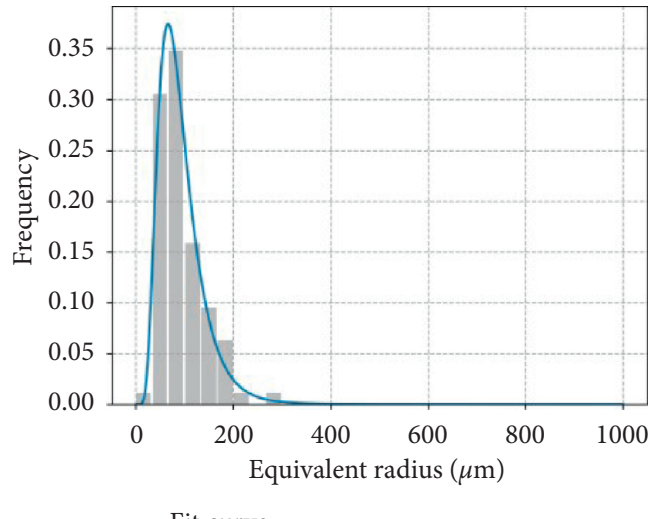

(d)

FIGURE 3: Mineral composition and microstructure of metagabbro. (a) Observation under a polarizing microscope. (b) XRD diffraction pattern. (c) Mineral composition. (d) Equivalent radius distribution curve of particles.

metagabbro is obviously higher than that of granite at lowstress level.

There are many defects and fractures in the metagabbro, and the compaction stage is more obvious, so the input energy is used to improve the stiffness of the rock. The dissipation energy ration of metagabbro and granite is stable in $0.06-0.1$ and $0.05-0.09$ during the elastic deformation stage. Distribution ratio is approximately the same, and the ratio of elastic energy density to dissipation energy density is about 9:1 in the linear development stage. The dissipation energy ratio increases with the stress level increase, and the closer to the peak strength is, the larger the increasing extent is. The dissipation energy ratio at the peak strength of metagabbro and granite is 0.15 and 0.13 , respectively. The extension of the elastic stage and reduction of the plastic stage lead to obvious improvement of rock energy storage capacity, and rock energy is released quickly at the moment of failure, which then causes strong impact failure.

\section{AE Characteristics}

5.1. AE Parameter Characteristics at Different Stress Levels. Given that $\mathrm{AE}$ signals are very sensitive to the initiation and growth of cracks in materials and structures, it has been widely used to evaluate damage mechanisms of rock. AE transducers were attached to the specimen to record AE data and to avoid background noise, and the trigger threshold was set to $40 \mathrm{~dB}$, where the peak definition time (PDT), hit definition time (HDT), and hit locking time (HLT) were set to 50,100 , and $500 \mu \mathrm{s}$, respectively, for the test. A layer of ultrasonic gel and tape were applied to provide better contact between the transducer and surface sample. The relationship among AE count, cumulative counts, AE energy, and load with time is depicted in Figure 7.

Compared with conventional uniaxial loading, rock under cyclic loading/unloading also undergoes compaction, linear development, stable crack propagation, unstable crack propagation, and rapid decline after peak. On the whole, the $\mathrm{AE}$ signals showed a slow increase in the elastic stage, a significant increase in unstable crack propagation, and a sharp increase in the failure stage.

Under the first cycle, the specimens are mainly in the compaction stage. There are fewer AE events as a result of crack closure and compaction. The cumulative counting curve shows the first rising step, but AE signals of the metagabbro in the compaction stage are obviously stronger than those of the granite, and even high-energy AE signals appear locally. The occurrence of local highenergy signals may be related to the rapid adjustment of the internal structure of metagabbro. At relatively low 


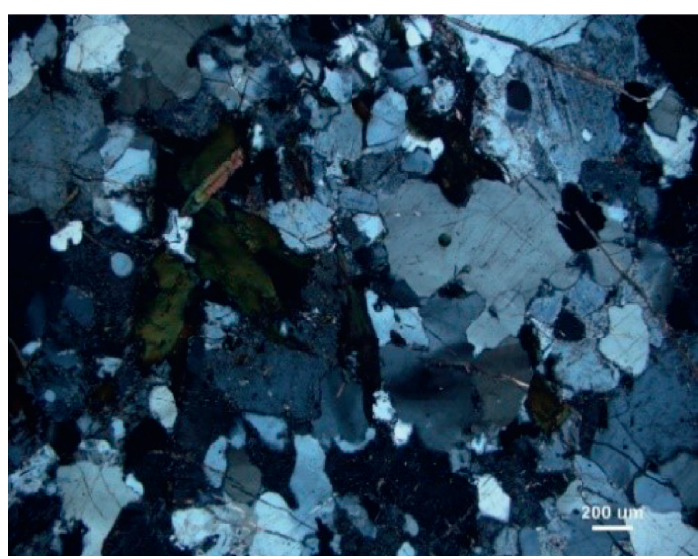

(a)

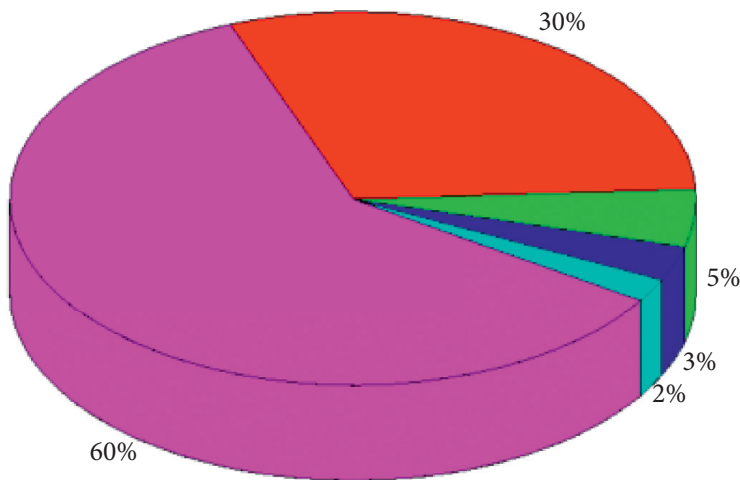

Plagioclase
Quartz
Biotite

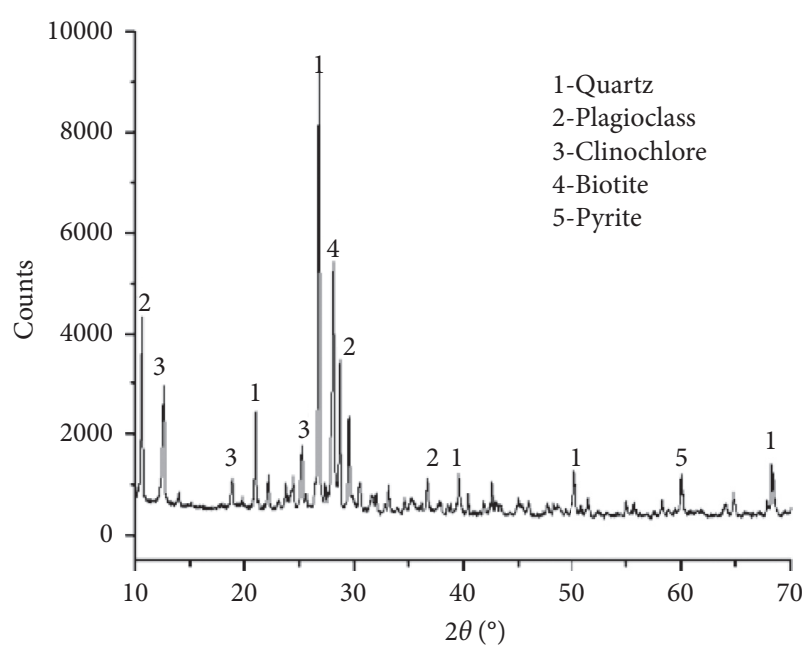

(b)

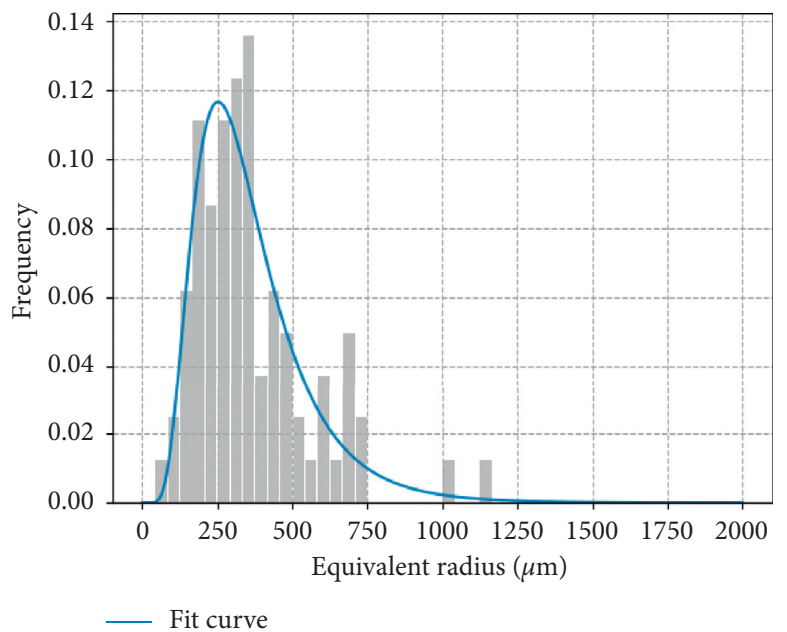

(d)

FIgURE 4: Mineral composition and microstructure of granite. (a) Observation under a polarizing microscope. (b) XRD diffraction pattern. (c) Mineral composition. (d) Equivalent radius distribution curve of particles.

stress, the stress did not play a primary role in the extension of microcrack intensity; microcrack propagation was related to the initial microcrack size, position, and direction.

Afterwards, the rock samples enter the elastic deformation stage corresponding to $47.4 \%$ and $65.7 \%$ stress levels, respectively. Elastic deformation is predominant and almost no new cracks occur. Although the cumulative ringing count curve of granite increases like a step, the gradient is small, and the cumulative ringing curve of metagabbro is nearly horizontal. During $47.4 \%-63.2 \%$ and $65.7 \%-76.4 \%$ stress level corresponding to granite and metagabbro, respectively, AE signals are gradually active, but the energy release is still at a lower level. As shown in Figure 7(a), the AE signals are almost symmetrically distributed at the maximum stress of this cycle, indicating that crack propagation stops immediately after unloading to last peak stress, and the rock sample is still in a weak damage state.
During $63.2 \%$ and $76.4 \%$ stress level to peak strength, the AE ringing count and energy release increase suddenly, and the cumulative ringing count increases abruptly. Obviously, the quiet phase of $\mathrm{AE}$ signals in the prepeak phase was not observed. Even at a lower stress level, the AE signals are still active in the unloading stage. In the unloading process, because of the elastic recovery of the element in the elastic state, there must be a friction effect between the elasticplastic parts (elements or particles). This friction should also be one of the physical mechanisms of AE during unloading.

New cracks and original cracks will continue to grow in rock under low stress level. When rock sample reaches its peak stress, a large amount of elastic energy stored in the rock sample will suddenly release along the direction most vulnerable to damage and then produce high-energy AE signals.

Before the failure of samples, the AE ringing count rate of granite is obviously higher than that of metagabbro. The $\mathrm{AE}$ energy released at the peak strength of granite is 


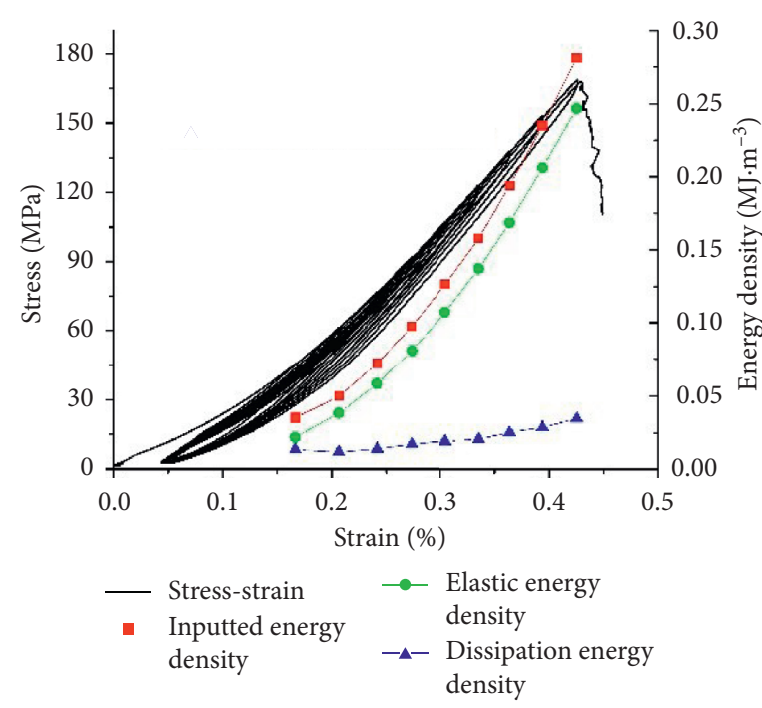

(a)

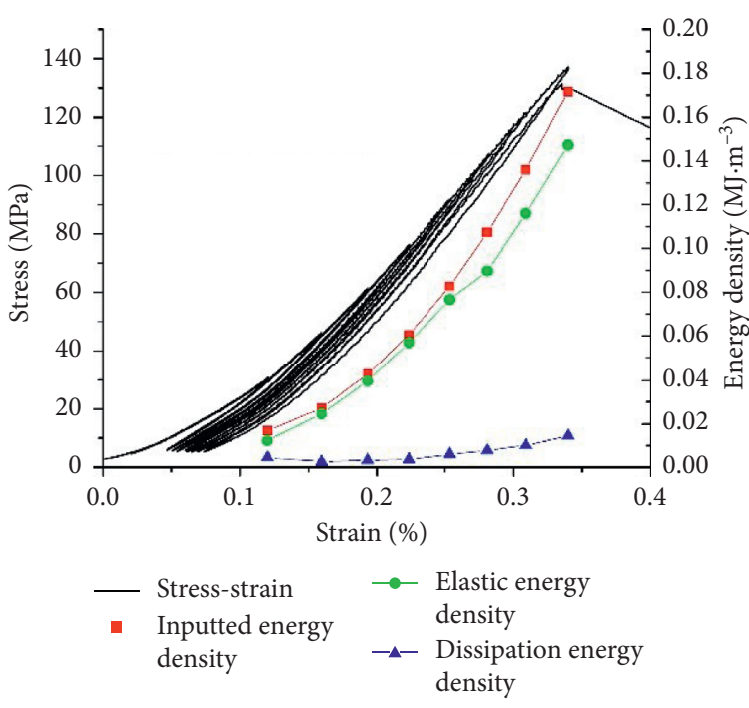

(b)

Figure 5: Energy evolution of (a) granite and (b) metagabbro.

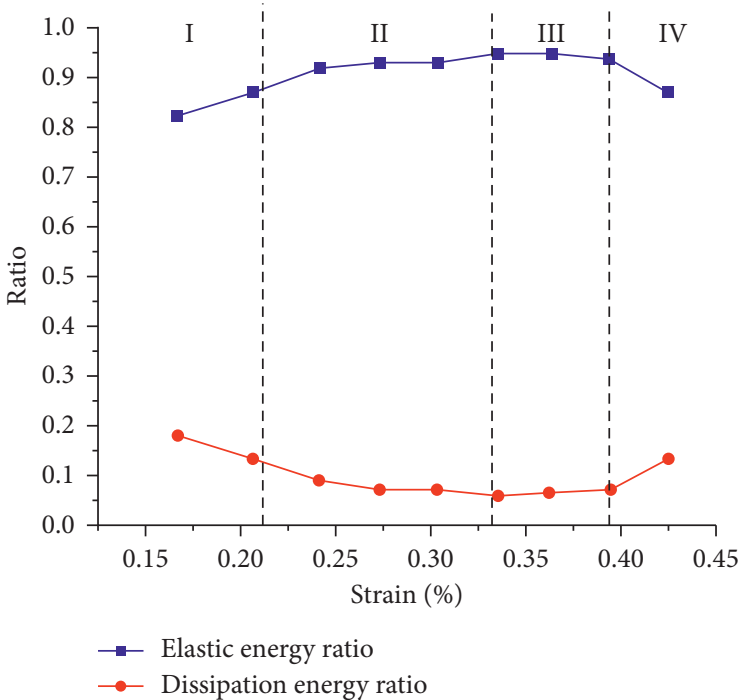

(a)

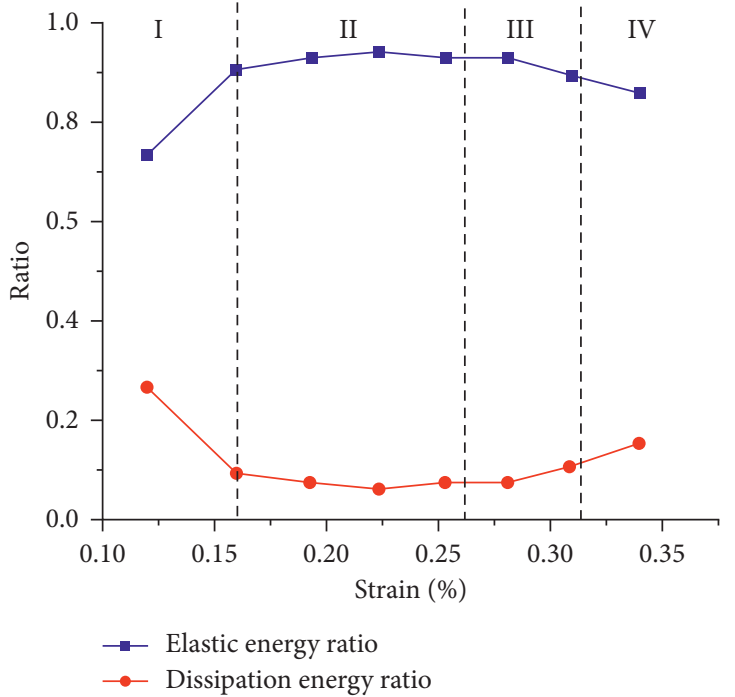

(b)

FIgURE 6: Energy distribution ratio of (a) granite and (b) metagabbro.

$2 \times 10^{6} \mathrm{aJ}$, and that energy released by metagabbro is about $6.5 \times 10^{4} \mathrm{aJ}$. The maximum release energy at the peak strength of granite is 30.77 times that of metagabbro, which indicates the severity of rock destruction. Therefore, it can be concluded that the rockburst proneness of rock is positively related to the $\mathrm{AE}$ energy released during failure.

5.2. AE Spectrum Characteristics. AE amplitude is a direct characterization parameter of crack propagation strength. The AE spectrum characteristics are determined by different crack growth modes. Therefore, amplitude and spectrum characteristics are of great significance to analyze the mechanism of rock crack, and AE spectrum characteristics under cyclic loading and unloading are depicted in Figure 8.
$\mathrm{AE}$ amplitudes of granite and metagabbro generated by cracks closure are concentrated in 40-60 dB and 40-45 dB, respectively. AE amplitudes are generally less than $50 \mathrm{~dB}$ in the elastic development stage. High-amplitude AE signals appear at each peak stress of loading/unloading and the $\mathrm{AE}$ amplitudes increase gradually with the stress level increase. However, at the same stress level, the $\mathrm{AE}$ amplitude of granite is generally higher than that of metagabbro. The amplitude of granite at the crack propagation stage changes with time in the form of arch bridge, which results in the absence of $40 \mathrm{~dB}-45 \mathrm{~dB}$ AE signals. When loading stress exceeds a certain stress level, the crack propagation is dominant in samples, and some crack initiation signals are concealed. But metagabbro did not occur above phenomena, and this is related to internal structure adjustment. The 

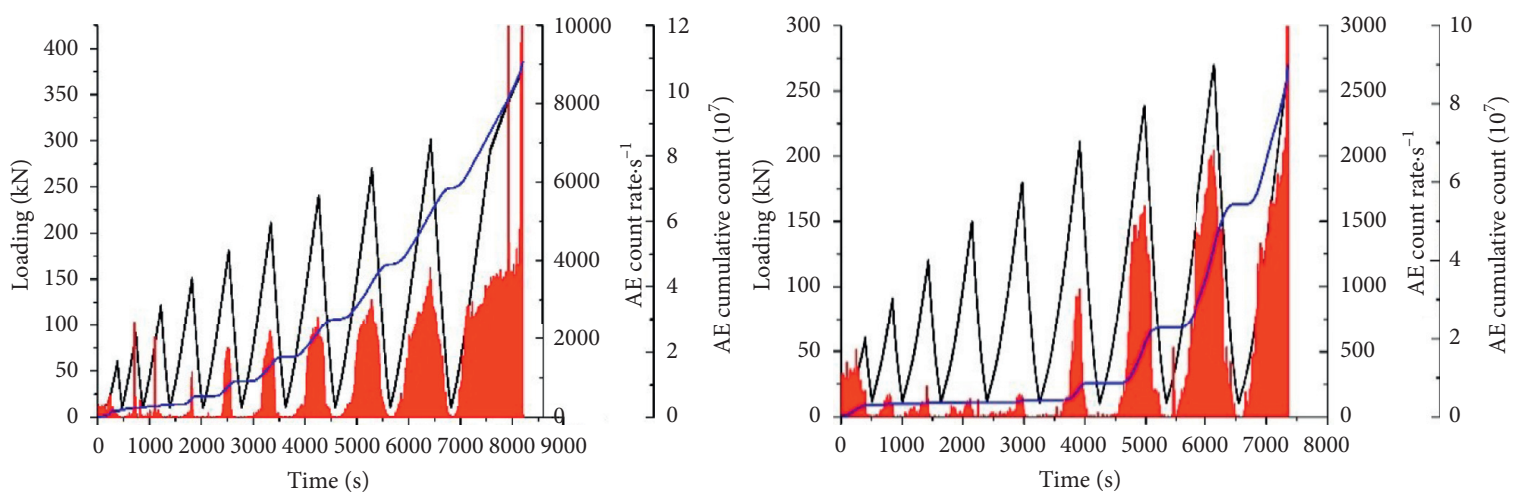

(a)
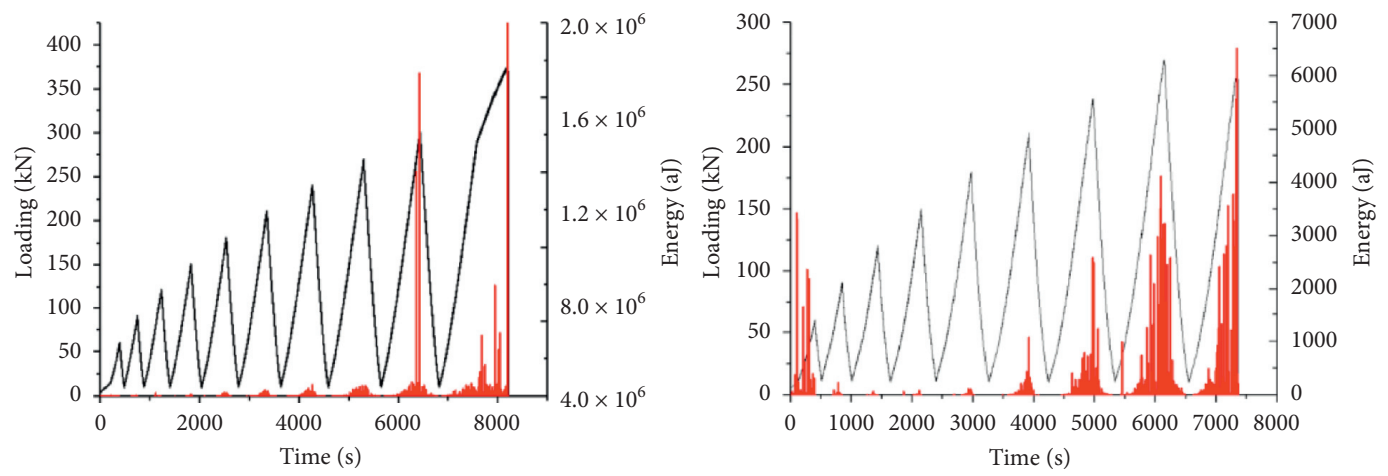

(b)

Figure 7: (a) AE count rate and cumulative count; (b) AE energy (left: granites; right: metagabbro).

maximum amplitude of granite and metagabbro at peak strength is $91 \mathrm{~dB}$ and $72 \mathrm{~dB}$, which also shows the intensity of released energy when samples are destroyed.

Throughout the whole cyclic loading/unloading process, the peak frequency of granite is mainly concentrated in the $20 \mathrm{kHz}$ and $50 \mathrm{kHz}$ bands. The frequency bands near $50 \mathrm{kHz}$ are dominant due to crack closure, and local high-frequency signals of $155-165 \mathrm{kHz}$ appear. New cracks are constantly generated in rock, and large-scale crack propagation occurs locally in the stable and unstable crack propagation stage, and the frequency range is $60-80 \mathrm{kHz}$. Therefore, it can be inferred that the large-scale crack propagation is concentrated in the frequency range of $60-80 \mathrm{kHz}$. AE signals of $155 \mathrm{kHz}$ highfrequency band appear near the peak strength of granite, and the high-frequency $\mathrm{AE}$ signals appear earlier than the peak strength. Therefore, the sudden increase of high-frequency signals indicates that macrofracture surface will occur in rock and it is about to enter the instability stage. The signal characteristics in the frequency band of metagabbro are similar to granite. In the unsteady crack propagation stage, $60-80 \mathrm{kHz}$ frequency band also appears, and the $\mathrm{AE}$ signals in $155 \mathrm{kHz}$ high-frequency band also appear at the peak strength. During 80-100\% stress level, the internal cracks expand fully and the $\mathrm{AE}$ signals increase obviously in the low-frequency range.

5.3. AE Felicity Ratio. The discovery of Kaiser effect was first made in metals by Dr Joseph Kaiser and reported in his doctoral thesis. Then it was extended to rock materials, and a lot of research studies on rock memory effect were carried out. Kaiser effect refers to the ability of rock to remember the maximum loading history. It is affected by loading history, loading mode, time effect, rock structure, and rock composition. Among these factors, loading history has the most significant effect on the AE characteristics of rock.

Kaiser effect is not obvious with the stress level increase, and rock memory deteriorates with the damage increase, and this phenomenon is called Felicity effect. The accuracy of Kaiser effect can be measured by the Felicity ratio, which is inversely proportional to the internal damage:

$$
R_{\mathrm{F}}(i)=\frac{\sigma_{\mathrm{AE}}}{\sigma_{(i-1)}},
$$

where $R_{\mathrm{F}}(i)$ is the Felicity ratio in $i$-th cycle. $\sigma_{\mathrm{AE}}$ is the stress level when the effective $\mathrm{AE}$ is restored during $i$-th loading process; $\sigma_{(i-1)}$ is the maximum stress level reached by $(i-1)$ th loading. In view of the ambiguity of the definition of "significant increase" of AE signals, in this paper, the stress threshold for $\sigma_{\mathrm{AE}}$ is set at AE counts greater than 100 for the granite and metagabbro specimens.

The variation in AE Felicity ratio of rocks with different rockburst proneness was basically consistent with cycle numbers (Figure 9). The $R_{\mathrm{F}}$ of granite and metagabbro can be divided into three phases, Phases I, II, and III. In Phase I, $R_{\mathrm{F}}$ is greater than one under low stress level (corresponding to below $58.3 \%$ and $77.8 \%$ stress levels, respectively), indicating that rocks have an obvious memory as a result of less damage. Rock samples are repeatedly compacted under 

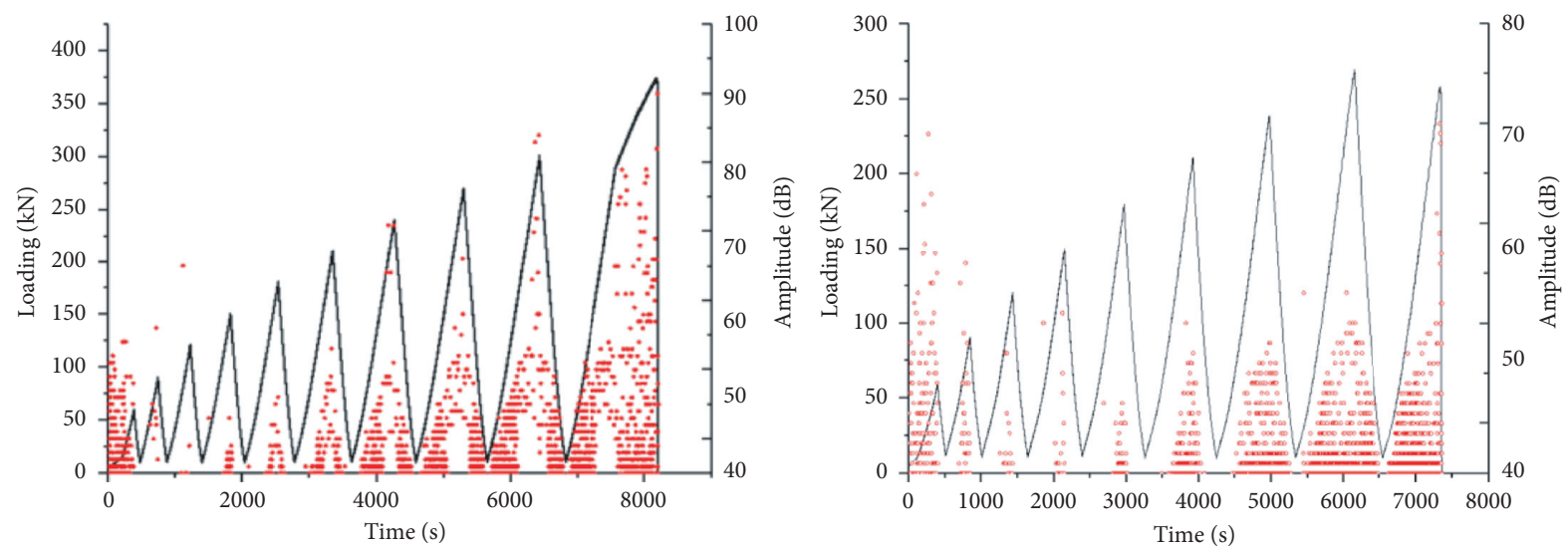

(a)
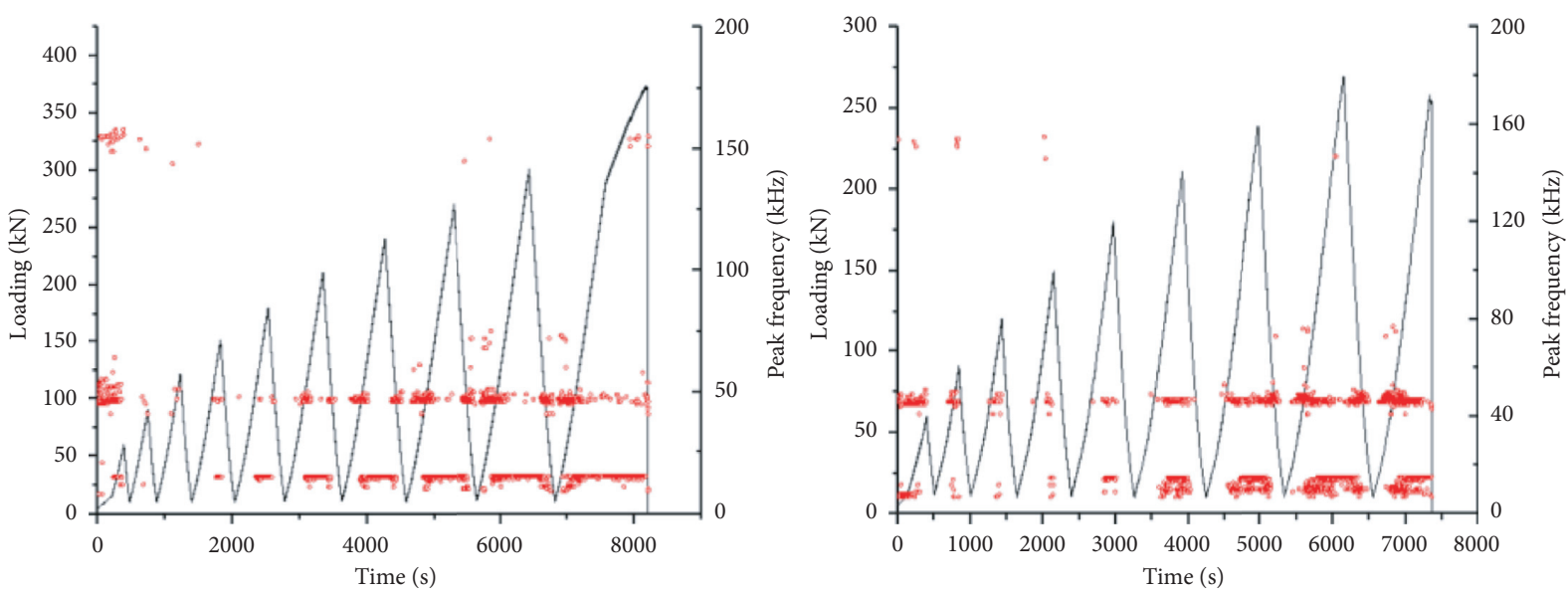

(b)

Figure 8: (a) AE amplitude and (b) AE peak frequency (left: granites; right: metagabbro).

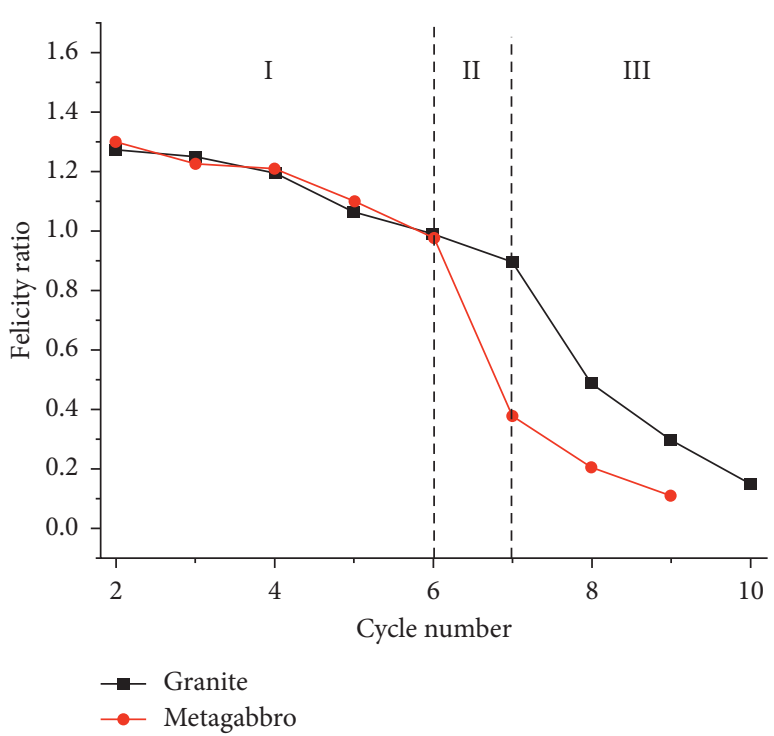

FIGURE 9: The relationship between Felicity ratio and cycle number.

loading, only the load exceeds previous maximum stress, and the significant AE signals will be generated. According to the energy distribution theory, the input energy is mainly stored in the form of elastic energy, while the dissipated energy by internal crack propagation is less.

In Phase II, $0.4<R_{\mathrm{F}}<1$, the $R_{\mathrm{F}}$ gradually declines as a result of increased damage. With the further increase of stress level, the cracks parallel to the loading direction expanded. $R_{\mathrm{F}}$ of metagabbro decreased by 0.6 from 0.98 to 0.38 , while $R_{\mathrm{F}}$ of granite decreased by 0.41 from 0.9 to 0.49 . The decline extent of $R_{\mathrm{F}}$ can be used to indicate the damage degree. The maximum drop of metagabbro is significantly greater than that of granite, stating clearly that the damage degree of metagabbro with the same stress increase is greater than that of granite. The internal damage of rock samples is mainly caused by the initiation and expansion of internal cracks, and the dissipation energy of rock samples increases gradually.

In Phase III, the $R_{\mathrm{F}}$ of granite and metagabbro decreased linearly after the eighth and seventh cycles, respectively, and the internal cracks were further extended due to the action of high-stress level. Owing to accumulated damage in rock samples, the cracks could expand continuously even at lowstress level and produce violent $\mathrm{AE}$ signals.

Overall, the changes in $R_{\mathrm{F}}$ for granite are generally the same as the changes in metagabbro. However, in the loading and unloading processes, the $\mathrm{AE}$ signals of granite 


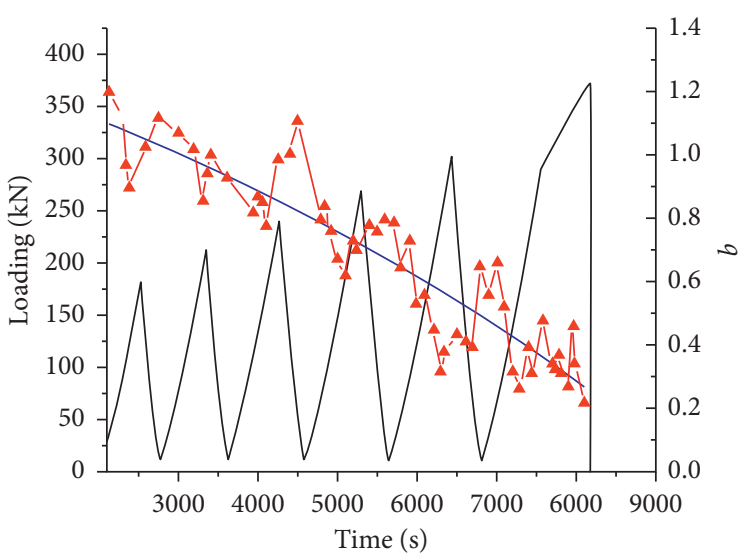

(a)

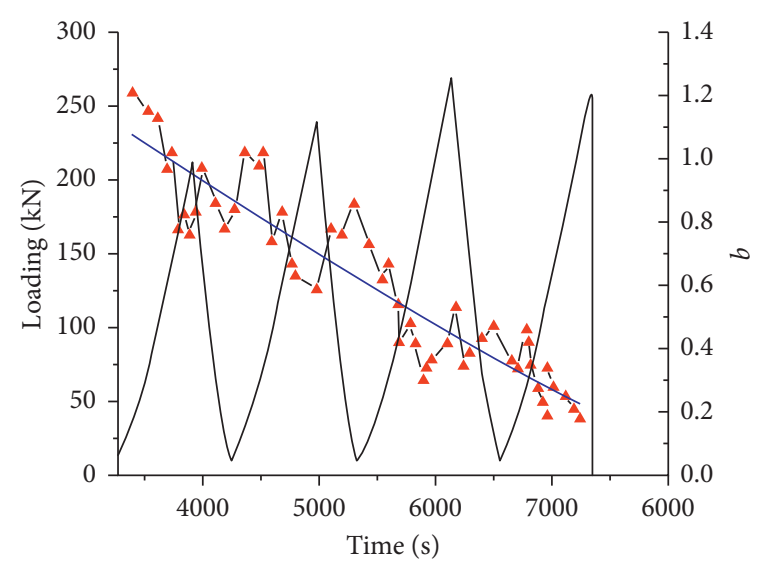

(b)

FIgURE 10: $b$-value variation with time of (a) granite and (b) metagabbro.

with strong storage energy capacity are stronger than those of metagabbro. Due to the release of elastic energy, the stress level of rapid $R_{\mathrm{F}}$ decline of granite is lower than that of metagabbro. However, the definition of $R_{\mathrm{F}}$ indicates that its value can only be used to determine the damage degree of rocks in the previous cycle, while this cycle damage can only be reflected in the next cycle, with a certain hysteresis.

5.4. AE b-Value. In consideration of the hysteresis of using Felicity ratio to characterize damage, this section studies the evolution of AE $b$-value during loading to discuss on the precursory information of rock failure.

In the field of earthquake seismology, it is well known that small-magnitude earthquakes frequently occur, whereas large-magnitude earthquakes occur rarely. Gutenberg and Richter [26] conducted a statistical analysis of a large number of seismic activities and obtained the following relationship between earthquake magnitude and frequency [27-30]:

$$
\lg N=a-b M
$$

where $M$ is the magnitude, $N$ is the earthquake frequency within $\Delta M$ range, $a$ and $b$ are constants, and $b$-value is an important parameter to evaluate the seismic activity level in a certain region. Since there is no concept of magnitude in $\mathrm{AE}$, the magnitude $M$ is usually replaced by the monitored AE amplitude during the experiment:

$$
M_{\mathrm{L}}=\frac{m}{20} \text {. }
$$

$M_{\mathrm{L}}$ represents the magnitude in the testing process, $b$ value was calculated by using the least square method, and the amplitude interval was equal to 0.5 . In order to avoid the experimental error caused by too few $\mathrm{AE}$ events at a certain stress level, this paper took 1000 acoustic emission events as a set of data and 100 acoustic emission events as sliding for calculation and obtained the variation law of $b$-value at different stress levels. $b$-value is the crack growth scale, reflecting the propagation and damage of cracks during loading. The decrease of $b$-value means that the proportion of major events in rock mass increases, so the large-scale microcracks increase. The changing trend of $\mathrm{AE} b$-value is the result of the game of crack scale development.

The $b$-value variation of granite and metagabbro during loading/unloading is investigated and shown in Figure 10, and the overall evolutionary law is similar. There is a clear downward trend with loading stress level increase, but the $b$ values of granite and metagabbro show their own characteristics at the same loading stress level. The AE $b$-values of granite and metagabbro are calculated from the $5^{\text {th }}$ and $6^{\text {th }}$ cycles, respectively. The AE signals produced at the lower stress level in the early stage are less, in order to ensure the calculation accuracy, and the AE $b$-values are not calculated at the lower stress level. AE $b$-values under medium stress level are relatively large, which concentrates in the range of $0.8-1.2$ and $0.62-1.12$, respectively. In the elastic development stage, the crack growth level and scale are limited mainly with low energy release rate. Under stable and unstable crack growth stage, high-stress level promotes some particles reaching its maximum bearing capacity, and the local stress is highly concentrated, leading to cracks growing and expanding. Therefore, AE signals with high amplitude and high energy are generated, and the $\mathrm{AE} b$-values decrease continuously. The $b$-values of granite and metagabbro decrease rapidly after ninth cycles and eighth cycles, while $b$ values fluctuate but remain at a low level. The nearer the peak stress is, the lower the $b$-value is.

In conclusion, the trend of $b$-value decrease with loading level increase also indicates that crack growth in different scales is a gradual development process from small scale to large scale. The damage degree of granite after peak stress is more severe than that of metagabbro, which is mainly due to less damage in front of the peak and rapid release of energy at the peak strength.

For each cycle, the $b$-value change tendency shows $\mathrm{V}$-shape, and the $\mathrm{V}$-shape is obvious under the condition of medium stress level, but $\mathrm{V}$-shape gradually disappears with 
the increase of stress level. AE $b$-value is a function of crack growth, and crack propagation and coalescence lead to a decline of $b$-value. However, crack grown stops immediately with stress drop under low-stress level, and almost no largescale cracks occur, so the $b$-value rises subsequently. However, with the cycle number increase, the cumulative damage will also generate obvious AE signals even at lowstress level. Large-scale cracks will be generated continuously through the internal cracks interaction, and $\mathrm{AE} b$ value will continue to decline. Accumulative internal damage results in new and existing crack expansion even at unloading stage, so the $\mathrm{AE} b$-value does not increase significantly, adversely continuing to decline. Under the last loading cycle, both granite and metagabbro show a rapid decrease of $b$-value. At this time, the internal cracks develop rapidly, macrofracture surface is produced, and dissipation energy increases sharply. However, the $b$-value of granite at the peak strength is obviously higher than that of metagabbro. The elastic stage of strong impact proneness granite takes up a relatively long proportion. Rock failure often concentrates in an instant. The overall loss of rock strength tends to be concentrated in a relatively short period of time. The large size crack monitored by AE signals before peak stress is smaller, so the $b$-value is larger. The lower the impact proneness is, the more fully the prepeak crack expands and the lower the sudden release of energy at the peak strength is. Although stress-induced changes in the $b$-value intuitively indicate the state of damage, one difficulty related to the use of the $b$-value to predict failure is that detectable changes in the $b$-value are generally the result of large changes in stress.

\section{Discussion}

With the stress increase, the crack size and numbers enlarge and then $\mathrm{AE} b$-value decreases obviously, showing fluctuating decline characteristics. However, with the further increase of stress level, the local stress concentration is easy to occur at the edge of large-scale cracks, and then microcracks are further developed at the edge of large-scale cracks. The number of microcracks is obviously larger than that of small-scale cracks, and then the low-amplitude and low-energy AE signals are released. At this time, the AE $b$ value increases slightly, which is the main reason for the fluctuating decline under higher stress level.

Under a higher stress level, the internal damage of rock sample accumulates, and the obvious AE phenomenon occurs during the unloading stage. This indicates that even at unloading stage, rock damage continues to increase and damage caused by unloading cannot be neglected. According to the definition of Felicity ratio, the Felicity ratio is the memory of the cumulative damage of rock mass, which cannot reasonably reflect the damage to rock mass caused by the last loading to the maximum point, and its value should be higher than the calculated value. The calculation definition of Felicity ratio illustrates that its value can only be used to determine the damage degree in the previous cycle, while the damage in this cycle needs to be reflected in the next cycle, which has a hysteretic effect.
The single $b$-value or Felicity ratio cannot accurately predict rock failure, so it is of great significance to improve the accuracy of rock failure prediction by considering the change rule of both before peak strength.

\section{Conclusion}

(1) Based on the comprehensive evaluation method of multiple rockburst proneness index, granite is mainly prone to strong rockburst and metagabbro is mainly prone to moderate rockburst. There is no obvious plastic deformation stage before the peak stress of two kinds of rocks, and the stress drops instantaneously after the peak strength.

(2) Rockburst proneness is positively correlated with mineral components with stable mechanical properties. Quartz and feldspar with stable mechanical properties in granite are obviously higher than that in metagabbro, which is the key element affecting rock impact tendency.

(3) Rocks with different rockburst proneness have similar energy evolution characteristics. The energy storage and dissipation capacity of rock are the direct reasons for rock impact in failure. The stronger the rockburst proneness is, the more the elastic strain energy is stored before the rock peak, and the less the dissipation energy is.

(4) The AE ring counts and energy of rocks with strong rockburst proneness and moderate rockburst proneness have similar evolution law. In quantity, rocks with strong rockburst proneness are obviously more than those with moderate rockburst proneness. In the aspect of $\mathrm{AE}$ spectrum, the peak frequency distribution of rocks with strong rockburst tendency is wider than that of rocks with moderate rockburst tendency.

(5) The peak frequency distribution of AE signals before the critical main fracture of rock shows the phenomenon of frequency band increase. Before the critical main fracture of rock with stronger rockburst proneness, the frequency distribution is more dispersed and the number of frequency bands is more.

(6) The single $b$-value and Felicity ratio can characterize the rock fracture process but both cannot accurately predict rock failure. Combining the change rule of both before peak strength is an effective way to improve the criterion of discrimination.

\section{Data Availability}

The data used to support the findings of this study are available from the corresponding author upon request.

\section{Conflicts of Interest}

The authors declare that there are no conflicts of interest regarding the publication of this paper. 


\section{Acknowledgments}

This paper was supported by the National Key Research and Development Plan (no. 2016YFC0600801), Key Program of National Natural Science Foundation of China no. (51534002), and Major Scientific and Technological Innovation Project of Shandong Province (no. 2019SDZY05).

\section{References}

[1] H. P. Xie, Y. Ju, L. Y. Li, and R. D. Peng, "Energy mechanism of deformation and failure of rock masses," Chinese Journal of Rock Mechanics and Engineering, vol. 27, no. 9, pp. 1729-1740, 2008.

[2] L. Y. Li, H. P. Xie, Y. P. Ju, X. Ma, and L. Wang, "Experimental investigations of releasable energy and dissipative energy within rock," Engineering Mechanics, vol. 28, no. 3, pp. 35-40, 2011.

[3] Z. Z. Zhang and F. Gao, "Research on nonlinear characteristics of rock energy evolution under uniaxial compression," Chinese Journal of Rock Mechanics and Engineering, vol. 31, no. 6, pp. 1198-1207, 2012.

[4] Z. Z. Zhang and F. Gao, "Confining pressure effect on rock energy," Chinese Journal of Rock Mechanics and Engineering, vol. 34, no. 1, pp. 1-11, 2015.

[5] Y. Y. Li, S. C. Zhang, Z. J. Wen et al., "Energy conversion and fragment distribution characteristics of coal sample under uniaxial cyclic loading," Journal of China Coal Society, vol. 44, no. 5, pp. 1411-1420, 2019.

[6] F. N. Jin, M. R. Jiang, and X. L. Gao, "Defining damage variable based on energy dissipation," Chinese Journal of Rock Mechanics and Engineering, vol. 23, no. 12, pp. 1976-1980, 2004.

[7] X. B. Yang, H. M. Cheng, J. Q. Lv et al., "Energy consumption ratio evolution law of sandstones under triaxial cyclic loading," Rock and Soil Mechanics, vol. 40, no. 10, pp. 1-8, 2019.

[8] H. P. Xie, R. D. Peng, Y. Ju, and H. Zhou, "On energy analysis of rock failure," Chinese Journal of Rock Mechanics and Engineering, vol. 24, no. 15, pp. 2063-2068, 2000.

[9] A. Farhidzadeh, A. C. Mpalaskas, T. E. Matikas, H. Farhidzadeh, and D. G. Aggelis, "Fracture mode identification in cementitious materials using supervised pattern recognition of acoustic emission features," Construction and Building Materials, vol. 67, no. 2, pp. 129-138, 2014.

[10] A. Behnia, H. K. Chai, and T. Shiotani, "Advanced structural health monitoring of concrete structures with the aid of acoustic emission," Construction and Building Materials, vol. 65, pp. 282-302, 2014.

[11] H. G. Ji, H. W. Wang, S. Z. Cao, Z. Hou, and Y. Jin, "Experimental research on frequency characteristics of acoustic emission signals under uniaxial compression of granite," Chinese Journal of Rock Mechanics and Engineering, vol. 31, no. 1, pp. 2900-2905, 2012.

[12] P. Zeng, Y.-J. Liu, H.-G. Ji, and C.-J. Li, "Coupling criteria and precursor identification characteristics of multi-band acoustic emission of gritstone fracture under uniaxial compression," Chinese Journal of Geotechnical Engineering, vol. 39, no. 3, pp. 509-517, 2017.

[13] M. C. He, F. Zhao, S. Du, and M.-J. Zheng, "Rockburst characteristics based on experimental tests under different unloading rates," Rock and Soil Mechanics, vol. 35, no. 10, pp. 2737-2747, 2014.

[14] M. C. He, F. Zhao, Y. Zhang, and S. Du, "Feature evolution of dominant frequency components in acoustic emissions of instantaneous strain-type granitic rockburst simulation tests," Rock and Soil Mechanics, vol. 36, no. 1, pp. 1-8, 2015.

[15] Y. B. Zhang, P. Liang, B. Z. Tian, X. Yao, L. Sun, and X. Liu, "Multi parameter coupling analysis of acoustic emission signals of granite disaster and the precursor characteristics of the main rupture," Chinese Journal of Rock Mechanics and Engineering, vol. 35, no. 11, pp. 2248-2258, 2016.

[16] Y.-B. Zhang, G.-Y. Yu, B.-Z. Tian, X.-X. Liu, P. Liang, and Y.-D. Wang, "Experimental study of acoustic emission signal dominant-frequency characteristics of rockburst in a granite tunnel," Rock and Soil Mechanics, vol. 38, no. 5, pp. 12581266, 2017.

[17] M. F. Cai, D. Ji, and Q. F. Guo, "Study of rockburst prediction based on in-situ stress measurement and theory of energy accumulation caused by mining disturbance," Chinese Journal of Rock Mechanics and Engineering, vol. 32, no. 10, pp. 1973-1980, 2013.

[18] S. J. Wang, "Geological nature of rock and its deduction for rock mechanics," Chinese Journal of Rock Mechanics and Engineering, vol. 28, no. 3, pp. 433-450, 2009.

[19] E. Johansson, Technological Properties of Rock Aggregates, Lule University of Technology, Luleå, Sweden, 2011.

[20] X. E. Li and S. H. Cai, "The microscopic analysis of the mechanical properties of granite in dam foundation of the Three Gorges Project," Journal of Chinese Electron Microscopy Society, vol. 14, no. 5, pp. 379-384, 1995.

[21] A. Tugrul and I. H. Zarif, "Correlation of mineralogical and textural characteristics with engineering properties of selected granitic rocks from turkey," Engineering Geology, vol. 51, no. 4, pp. 303-317, 1999.

[22] R. Prikryl, "Some microstructural aspects of strength variation in rocks," International Journal of Rock Mechanics \& Mining Sciences, vol. 38, no. 5, pp. 671-682, 2001.

[23] T. Keikha and H. Keykha, "Between mineralogical characteristics and engineering properties of granitic rocks," The Electronic Journal of Geotechnical Engineering, vol. 18, pp. 4055-4065, 2013.

[24] X. Wang, W. Yuan, Y. T. Yan, and X. Zhang, "Scale effect of mechanical properties of jointed rock mass: a numerical study based on particle flow code," Geomechanics and Engineering, vol. 21, no. 3, pp. 259-268, 2020.

[25] G. Zhang, P. G. Ranjith, D. Li, A. Wanniarachchi, and B. Zhang, "In-situ synchrotron X-ray microtomography observations of fracture network evolution of coal due to waterflooding," Geophysical Research Letters, vol. 47, no. 10, Article ID e2020GL087375, 2020.

[26] B. Gutenberg and C. F. Richter, "Earthquake magnitude, intensity, energy, and acceleration," Bulletin of the Seismological Society of America, vol. 32, no. 3, pp. 163-191, 1942.

[27] S. J. D. Cox and P. G. Meridith, "Micro cracking formation and material softening in rock measured by monitoring acoustic emissions," International Journal of Rock Mechanics and Mining Sciences, vol. 30, no. 1, pp. 11-24, 1983.

[28] D. L. Turcotte, W. L. Newman, and R. Shcherbakov, "Micro and macroscopic models of rock fracture," Geophysical Journal International, vol. 152, no. 3, pp. 712-728, 2003.

[29] C. G. Hatton, I. G. Main, and P. G. Meredith, "A comparison of seismic and structural measurements of scaling exponents during tensile sub-critical crack growth," Journal of Structural Geology, vol. 15, no. 12, pp. 1485-1495, 1993.

[30] M. V. M. S. Rao and K. J. P. Lakshmi, "Analysis of b-value and improved b-value of acoustic emissions accompanying rock fracture," Current Science, vol. 89, no. 9, pp. 1577-1582, 2005. 